\title{
Counterfeit drugs and the online pharmaceutical trade, a threat to public safety
}

\begin{abstract}
Counterfeit pharmaceuticals are a serious and ever-growing threat to public safety. Monitoring the trade is difficult, resulting in the precise scale of the problem being unknown, however evidence shows that it is not just lifestyle drugs that are targeted nowadays. Adverse health problems, including fatalities, have resulted from consumers self-medicating with counterfeit products. Without efforts to enhance the public's knowledge, the problem will continue to persist. The internet is facilitating the trade by providing counterfeiters with a large consumer base and limited risks. The dark net within it allows for anonymous transactions between manufacturer, distributer and consumer. While some online pharmacies are legitimate, there are a growing number of those that are unverified which sell dangerous counterfeit products. Both the packaging and medication are becoming increasingly sophisticated, making it difficult for consumers and law enforcement to identify them without chemical analysis. Counterfeit batches have also been detected in established legal trade routes whereby they are able to, if undetected, end up in high street pharmacies and hospitals. Multiple organisations have set up worldwide operations to dismantle the trade however this is a complex and evolving problem that without significant changes to legislation may never be fully
\end{abstract}

Keywords: Counterfeit, pharmaceuticals, online pharmacy, internet drug access, public health
Volume 6 Issue 3 - 2018

\author{
Andrew O'Hagan, April Garlington \\ Department of Science and Technology Nottingham Trent \\ University, United Kingdom
}

\begin{abstract}
Correspondence: Andrew O'Hagan, Department of Science and Technology Nottingham Trent University, Clifton Lane, Nottingham NGII 8NS, United Kingdom, Tel +447-950-875563, Email andrew.ohagen@ntu.ac.uk
\end{abstract}

Received: May 07, 2018 | Published: May 222018

\section{Introduction}

Substandard, spurious, falsely labelled, falsified and counterfeit (SSFFC) medical products ${ }^{1}$ are each year becoming an increasing threat to consumers' health and the problem remains largely underreported. ${ }^{2}$ SSFFC's is a term defined by members of state which identifies the products associated with the illicit trade. Although there is currently no agreed definition, counterfeit medicines were previously defined by the World Health Organisation (WHO) as "one which is deliberately and fraudulently mislabelled with respect to identity and/or source. Counterfeiting can apply to both branded and generic products, and counterfeit products may include products with the correct ingredients or with the wrong ingredients, without active ingredients, with insufficient (inadequate quantities of ingredient(s), or with counterfeit packaging." "It should be noted that counterfeit and substandard do not necessarily equate to the same meaning. Substandard purely refers to products being manufactured to a poorer quality than that which is established for effectiveness. ${ }^{4}$ There is a common misconception that the counterfeit market is only prevalent in poorer, developing countries, largely due to the lack of training and testing within their hospitals making them acutely vulnerable ${ }^{5}$ however it is a worldwide problem. In the United Kingdom (UK) the size of the illegal drug market is unknown; ${ }^{6}$ it is reported to be far more common for 'self enhancement' products to be purchased online rather than antibiotics and vaccinations, however the sale of cancer and heart disease treatments are progressively rising. ${ }^{7,8}$ As recently as 2013, a south-west England city was under investigation for the purchase and supply of illicit steroids and other performance and image enhancing drugs (PIED). ${ }^{9}$

\section{History}

During the mid- $19^{\text {th }}$ century the adulteration of pharmaceuticals was prevalent in the UK and USA, with quinine being largely falsified. ${ }^{10}$ Although sophisticated drug counterfeiting is a relatively modern problem, general counterfeiting of goods, including currency, by criminal networks is a long-standing and deep-rooted issue. Ever since economic transactions started to be managed by market and currency systems, these groups have used illicit products to turn out profits and evade taxation. ${ }^{11}$ The widespread phenomenon that is counterfeit drug trafficking was first acknowledged as a problem by the WHO in $1985^{\circ}$ with the issue first being discussed at length in 1998 at the World Health Assembly. ${ }^{12}$ Over the past two decades, the evidence supporting their claim has steadily increased ${ }^{13}$ with new cases being discovered weekly. ${ }^{14}$ When the issue was first brought to attention in developed countries, the counterfeit market tended to focus on expensive lifestyle drugs ${ }^{13}$ with the most commonly abused being sildenafil citrate, more commonly known as Viagra. ${ }^{15}$ As times have progressed, counterfeiters now tend to take advantage of whatever is in high demand, which currently has spread too anticancer, antivirals and diabetic medication. ${ }^{8}$ Although the UK does not tend to produce the illicit products, it is one of the many wealthy countries targeted by counterfeiters due to the vast potential for profit. ${ }^{16}$ The Medicines \& Healthcare products Regulatory Agency (MHRA) have stated that the UK is being used as a "transit point, distribution hub and end-user" for these products. ${ }^{17}$

Since late 1990s the sale of SSFFC's through internet based pharmacies has been a recognised problem. ${ }^{18}$ Online criminals have anonymity, which gives them security whilst having access to the global consumer. ${ }^{19}$ Criminal activity around this area is highly attractive due to the low risk, high profit nature. Top priority action is not considered necessary by law enforcers, resulting in the penalties that the majority of countries give being far less severe than those of serious level crimes..$^{20}$ Another appeal to modern organised crime groups is that logistically the distribution of the products is simple, 
by abusing the existing legitimate supply chains (Figure 1). By exploiting this, the distribution is widespread, reliable and detection risk is limited. ${ }^{20}$ However for consumers this results in pharmacies and hospitals not always being considered safe..$^{22}$ Counterfeiting appears across most therapeutic classes, with both branded and generic medicines being targeted ${ }^{22}$ along with medical products including syringes and medical equipment ${ }^{23}$ such as blood glucose test strips. ${ }^{24}$ Local law enforcement tends to have little knowledge of the issue therefore allocating resources to help tackle the problem remain low priority. ${ }^{19}$ Due to this lack of awareness, consumers, who mostly do not think to question the authenticity of their medical products, are found to be at a disadvantage.

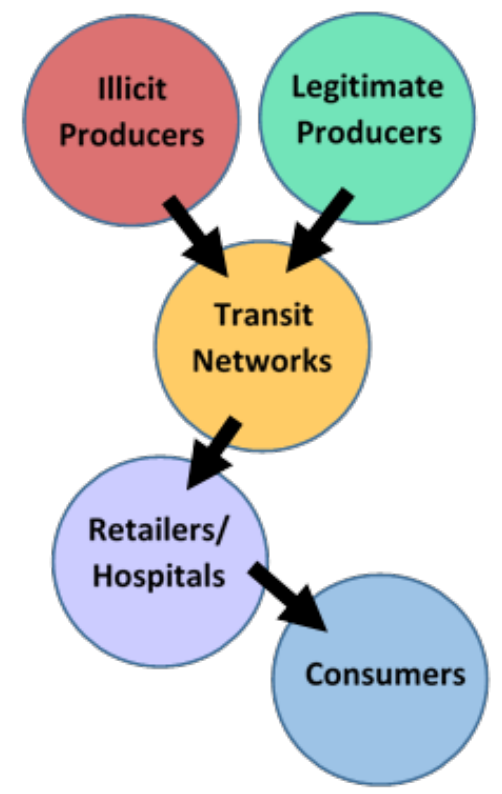

Figure 1 Supply route of counterfeit drugs through legitimate supply chains. ${ }^{21}$

\section{Scale of the problem}

With global economy expansion and ease of access to the internet, a strong and secure foundation for counterfeit operations is now achievable. ${ }^{19}$ Despite quantifying the illicit goods trade being exceedingly challenging, in 2011 the World Economic Forum reported that it was thought to represent $7-10 \%$ of the global economy. ${ }^{25}$ Pharmaceutical counterfeiting has shown an increase in recent years, with the whole world now being aware of the problem. ${ }^{14}$ Although the overall scope of the market remains unknown, it has been approximated that $10 \%$ of drugs sold worldwide are counterfeit, ${ }^{13}$ with the prevalence of these drugs in certain areas of Africa and Asia believing to have reached $70 \% .{ }^{26}$ Based on public sources, estimations of the market size were made, the results of this can be seen in Table 1. Even though these are only rough approximations, it is evident that the counterfeit pharmaceutical market is thriving and seeming to bring in more profit than any one classic illicit drug. Without definite legislation being put in place, the figure of $\$ 200$ billion per year is likely to continue to grow. ${ }^{25}$ The UK was found to be ranked $7^{\text {th }}$ in a 2006 poll carried out by the Pharmaceutical Security Institute looking at the number of counterfeit drugs discovered and seized in countries worldwide. ${ }^{27}$ There are two main reasons as to why the UK is targeted, the first is due to the convenient location. Counterfeiters use the UK as a transit point from Asia to reach consumers based in the USA and Western European. The second is as an end user market; due to the increased prices and consumption seen here, the profits capable of being produced in the UK are huge. ${ }^{27}$ It remains highly concerning that there is a strong correlation between the increase sale and distribution of counterfeit drugs and the growth of microbial resistance. This will in due course lead to increase costs and further strain on the healthcare system ${ }^{18,26}$ and potentially result in lifesaving medicines becoming ineffective.

Table 1 Estimated market size of illicit goods represented in USD billion per year ${ }^{25}$

\begin{tabular}{ll}
\hline Illicit Good & $\begin{array}{l}\text { Estimated annual market } \\
\text { size (USD billion) }\end{array}$ \\
\hline Counterfeit pharmaceutical drugs & 200 \\
Prostitution & 190 \\
Marijuana & 140 \\
Counterfeit electronics & 100 \\
Cocaine & 80 \\
Opium and heroin & 60 \\
Web video piracy & 60 \\
Software piracy & 50 \\
Cigarette smuggling & 50 \\
Human trafficking & 30 \\
Environmental crimes and natural & 20 \\
resources trade & 5 \\
Logging & 5 \\
Art and cultural artefacts & 1 \\
Small arms &
\end{tabular}

Serious security issues arise from importation and re-importation as this allows for counterfeit batches to more easily enter the countries legitimate supply chain. They can then be distributed to pharmacies and hospitals who unknowingly then supply them to patients. ${ }^{13}$ In 2005 the U.S. Food and Drug Administration (FDA) were required to recall a counterfeit batch of "Lipitor", an atorvastatin used to treat high cholesterol, that had been sold into the UK. ${ }^{28}$ Due to the counterfeit product being distributed, there were worries as to its quality and effectiveness. After initial investigations it was found to not pose an immediate health risk however patients were still advised to stop taking the drug and return it to the establishment they had received it from. Although in this case the counterfeit Lipitor did not cause adverse effects to health, it did result in a decline in consumer confidence in the genuine product and the pharmacy that supplied them with it. ${ }^{17}$

\section{Organised crime}

With relatively low risk for high profits compared to cocaine, crack or heroin; it is hardly surprising that organised criminal groups have taken an interest in the counterfeit licit drug trade. ${ }^{29}$ Pfizer, the pharmaceutical company that manufacture and license Viagra, compared the profitability of Viagra to heroin. They found that $1 \mathrm{~kg}$ of heroin had higher production costs with lower street value than the same quantity of Viagra. The MHRA investigated a case whereby 100,000 counterfeit Viagra pills were imported into the UK from a Chinese manufacturer at approximately 25 pence each with a resale value of up to $£ 20$ each, resulting in a profit of $£ 1.6$ million. ${ }^{30}$ Criminal 
gangs including the Russian mafia, Colombian drug cartels, Chinese triads and Mexican drug gangs ${ }^{21}$ have become involved in the trade, so much so that now organised crime is largely responsible for the entire market. ${ }^{31}$ With large networks and vast resources ${ }^{32}$ they are able to maintain complex structures over long periods of time and avoid additional costs by using already existing trafficking routes,${ }^{31}$ making this a far more sophisticated issue. Further evidence is present that establishes connections between pharmaceutical counterfeiting and illicit drug production, trafficking and money laundering. ${ }^{31}$ In 2008, Canadian police reported seizing ecstasy and methamphetamine pills alongside counterfeit Viagra and Cialis tablets. ${ }^{31}$ In addition to this, increasing evidence highlights the involvement of Hezbollah and al Qaeda $^{21}$ who are using the profits to fund terrorist activities. ${ }^{22}$ This was brought to light in 2006 when 19 individuals, who were running a terrorist ring, were charged after selling counterfeit drugs and other contraband to support the activities of Hezbollah. ${ }^{29,33}$

\section{Dangers of SSFFC medicines}

Prescription drug abuse has been described as "second only to marijuana abuse" with the user achieving a false sense of security due to them being FDA approved, ${ }^{34}$ however consumers who purchase from illicit sources face devastating health and safety risks. Not only does the consumer suffer due to the sale of SSFFC's but so does the economy, as the counterfeit market reduces the profits made by legitimate drug companies. ${ }^{35}$ Despite governments worldwide facing tax revenue losses, budget is having to be allocated in attempts to tackle the problem. ${ }^{19}$ Annually it is estimated that over half a million deaths are caused directly by counterfeit medicines. ${ }^{30}$ The exact number who have suffered or died, however, is not easily distinguishable due to direct links not always being evident and in many case people are not aware they have taken falsified medication. ${ }^{26}$ A UK based survey of general practitioners found that $25 \%$ had been required to treat patients who were suffering side effects from drugs they had purchased online. ${ }^{26}$ Particular concern arises when counterfeiters reduce the quantity of active ingredients present within the medication, ${ }^{4}$ often leading to the addition of an undeclared lethal active ingredient as an alternative. ${ }^{36}$ If an unknown is added consumers are at risk of serious harm as they are unaware of what they are ingesting. This became evident at a children's hospital in Bangladesh where in excess of 400 children lost their lives after being administered an adulterated paracetamol which lead to renal failure.$^{37}$ Potentially even more dangerous and indirectly causing more deaths annually than once thought, is that with a lower concentration of active ingredients, consumers with life threatening illnesses may think they are treating the disease only to discover that the medication is not working in the desired way.

There is always concern with unregulated medications as good manufacturing practice is not necessarily preformed during production. In the UK anabolic-androgenic steroids (AAS) are controlled under the Misuse of Drugs Act, Schedule 4, Part 2. Classified as a class C, it is an offence to sell or supply steroids and to possess them without a prescription. ${ }^{38}$ Despite the UK having legislation controlling AAS use in competitive sport, this has not stopped the distribution online or via the black market. UK females are increasingly abusing recombinant human growth hormone (rhGH) in the form of intramuscular injections. ${ }^{39}$ Due to non-sterilised counterfeit products being purchased there has been a spike in the number of cases of intramuscular abscesses, as shown in Figure 2. In 2009, the World AntiDoping Agency (WADA) investigated 57 tablets to identify the degree to which counterfeit products were accessible. It was determined that $42 \%$ of those tested were counterfeit, either containing different steroids to what was declared or none at all.

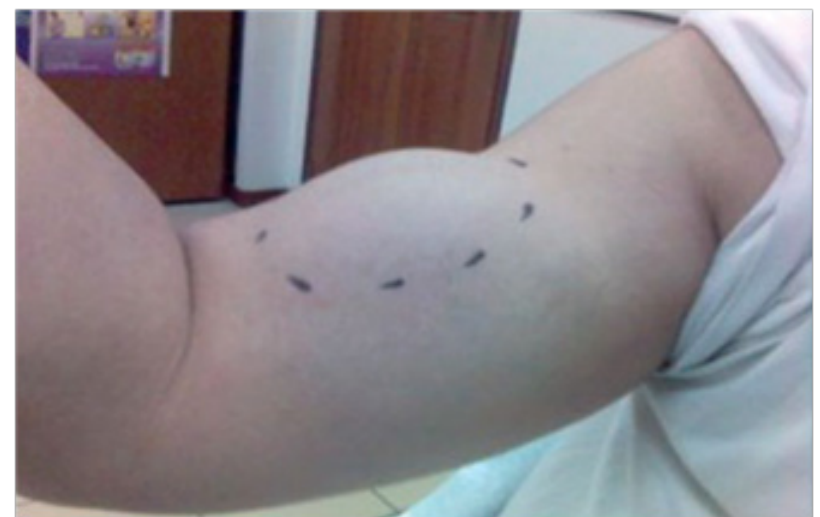

Figure 2 Intra-muscular abscess of the right bicep. ${ }^{39}$

\section{The degree to which the internet has assisted counterfeiters}

Living in a dynamic world with the global consumer having continual access to broadband ${ }^{40}$ it is hardly surprising that online drug markets have vastly grown in popularity when compared to local community pharmacies. 1999 showed rise to the first exclusively online pharmacy in Europe ${ }^{41}$ and in the same year came the first case of online distribution to make headlines. Dr Pasos, an orthopaedic surgeon, was accused of unprofessional conduct after prescribing Viagra to a Russian sailor who was in the Atlantic at the time. ${ }^{42}$ In general terms an online pharmacy (OP) is an organisation that allows consumers to purchase pharmaceuticals, including prescription-only medication, via an online ordering and mail delivery system..$^{18}$ Legitimate OPs will request registration and card payment information as well as requesting that a prescription be sent, usually by post, before the order will be shipped. ${ }^{7}$ Without a valid prescription, signed by a doctor, the supply of these medications is illegal. More commonly referred to as the dark net, The Onion Router (TOR) network is an encrypted area of the internet allowing for anonymous communications with no trace of website history or physical location. ${ }^{43}$ This is an easily accessible and private means for accessing drugs across the border. However, with few OPs based in Europe, ${ }^{41}$ partial regulation and varying legislation depending on where in the world the company is based, it has become an almost 'safe' place for counterfeiters to operate. Internet security experts estimate that 15 billion $^{30}$ spam emails advertising the services of these websites are sent each day and reach virtually everyone in Europe. It is likely that the majority of sites accessed through this method are counterfeit. For most, these emails are seen as no more than an irritation that are swiftly sent to the junk folder, but even if only a minor proportion of individuals react and purchase the products on offer, this could easily account for tens of thousands of sales each day. $^{7}$

\section{The virtual interface}

The internet has greatly increased the complexity of the counterfeit drug trade ${ }^{22}$ and one fact is certain, the safety of these OPs is highly associated with geographical location. "Brick-and-mortar" OPs tend to be an extension of a high street pharmacy that can be visited by customers. ${ }^{44}$ The questionable safety of buying online tends to be when the business exists purely in cyberspace. They tend to be lightly 
monitored and work largely outside the law. ${ }^{45}$ In a sample population of 118 OPs more than half $(56.8 \%)$ only had a virtual interface, however of those that did give a geographical location only in $54.9 \%$ of the sites did this location match the area of domain registration. ${ }^{46}$ Illicit marketing has also seen a shift from designated internet search engine websites to advertising on multiple social media websites. ${ }^{47}$ This sets to escalate the number of individuals who are likely to see the adverts and use these OPs. This also offers counterfeiters an increase reach to a younger and more vulnerable consumer base.

\section{The appeal of online counterfeiting}

The pharmaceutical industry is one of the largest in the world and where demand is present there are criminals willing to take advantage. The internet has simplified the drug trade and allows for a wider customer base to be established. ${ }^{27}$ With low production costs, the profit margin on illicit pharmaceuticals is huge. World Finance ${ }^{32}$ estimates that, in excess of 800 pharmaceuticals have counterfeit versions in circulation globally. They estimate that in developing countries, such as India or China, Viagra can be purchased for \$60/ $\mathrm{kg}$ and when transformed into $25 \mathrm{mg}$ tablets, can be sold for $\$ 200,000$. Some counterfeiters add cutting agents prior to the tablets being formed, this will increase the product that is available for sale which is an attraction for the producer as a higher income will be achieved, but a problem for consumer due to reductions in the declared active ingredient present. The appeal of this highly profitable business is heightened by the ineffective legislation that is present in the UK. The current legal framework allows the MHRA to prosecute those who produce and distribute counterfeit products within the UK, however the law also allows for individuals to import products for personal use, providing they are licenced in this country. ${ }^{16}$ These products can be ordered online from countries that do not comply with the same quality control standards as expected in the UK. Selling counterfeit medicines is currently regulated under intellectual property crime and infringement. ${ }^{48}$ These lax laws allow counterfeiters to receive lighter punishments than those given to criminals who supply classic illicit drugs, ${ }^{49}$ despite the dangers to consumers being just as high.

\section{Who uses these sites?}

John Clark, leader of Pfizer's Global Security team estimates that in the UK 2 million people buy prescription medication online. ${ }^{26}$ In 2009, a UK based survey of 2076 adults carried out by the MHRA into bypassing the healthcare system revealed that $15 \%$ had purchased medical products online without a prescription. ${ }^{50}$ Internet pharmacies offer an attractive appeal to various patient populations. There are those that, despite valuing the consultations received by healthcare professionals, find the lower prices or ease of access the internet offers too enticing. This is especially true for those who are financially strained or with limited mobility, including the disabled and elderly, where accessing doctor surgeries may cause difficulties. The main groups that counterfeiters thrive off however, are those individuals looking to avoid the doctors and the healthcare systems altogether. ${ }^{51}$ These may be individuals looking for lifestyle drugs due to conditions including obesity, hair loss and male impotence which cause embarrassment, or drug addicts looking for their fixes in a more secretive way. Both will be far less likely to confide in a doctor if problems arise, instead tending to purchase a new online. Tramadol, amphetamine, methamphetamine and codeine, all drugs that have an inherent risk of being dangerous to health and strongly addictive, are facilitating abuse by being readily available online. ${ }^{46}$

\section{Requirement of prescription}

The sale of controlled substances without a valid prescription is illegal in the UK due to consumers not having the required knowledge to competently medicate themselves. Prescriptions permit for follow up sessions with the prescribing medical practitioner to ensure the drug is having the required effect and therefore allowing quality standards to be upheld. ${ }^{18}$ In the case of certain OPs, rather that asking for a prescription the website will take the consumer through an online questionnaire that aims to evaluate their health status. No standardised test exists, so the competency of this method is questionable. In a 2007 study ${ }^{46}$ it was found that only $18.6 \%$ of the 118 sample population of OPs asked for a valid prescription signed by a physician. Of the $81.4 \%$ that did not request this, $68.8 \%$ required their customers to fill out a medical questionnaire. The remaining $31.6 \%$ did not require any information in order to make a purchase. Orizio et al. ${ }^{52}$ investigated 57 OPs in 2009 that use these questionnaires. They reported that many were already completed with negative answers prior to starting and that they could, in most cases, be submitted incomplete. It was concluded that the presence of these tests was more likely to give the consumer a sense of security rather than an actual assessment of health. It has also been seen that those who do not require a prescription or offer online consultations attempt to create an image of transparency and honesty, often achieved by giving comprehensive information about the online transaction system, security of payment, and origin of drugs. ${ }^{53}$ Although it is known from other studies that this is not always accurate

\section{Advertising strategies}

OPs tend to amplify the aspects that will appeal to consumers while overshadowing the risks and dangers behind the products. ${ }^{54}$ Orizio et al. ${ }^{46}$ compared the promotion of drugs between pharmacies that require a prescription and those that do not. Illustrated in Figure 3, it is clearly seen that those which do not require a prescription, use far more advertising strategies, including the idea that patients can avoid seeing a physician. This confidentiality that buying online offers is one of the key selling techniques; boasting advantages of not only avoiding medical professionals but with discreet packaging, no one needs to be aware of what you are taking. ${ }^{18}$ The lower price associated with buying online is a major appeal to many consumers, however it is not always as good value as it may seem on the surface. As determined by Levaggi, ${ }^{55}$ consumers buying drugs without a prescription spent more than those who did and that in order to achieve the cheaper pricing it was required that items be bought in higher quantities, this was also found by Armstrong. ${ }^{56}$ In order to promote bulk purchases a reduced number of side effects tend to be declared, that way encouraging the consumer to believe that prolonged exposure to the drug will only be advantageous to their life. ${ }^{55}$

\section{Packaging}

Consumers and authorities are finding it increasing difficult to identify illicit versions of medication through visual inspection alone. ${ }^{24}$ Despite the legitimate pharmaceutical industry consistently implementing new measures to help to protect genuine products and allow for easier distinction from counterfeit products, ${ }^{14}$ criminals are able to quickly adapt to these modifications with the help of rapidly enhancing technology. ${ }^{4}$ As shown in Figure 4, technological advances have greatly enhanced counterfeiters' ability to create packaging that is exceptionally close to the drugs authentic packaging. ${ }^{4}$ Criminals are becoming increasingly able to mimic logos using colour shifting 
inks and holographs. ${ }^{57}$ Tools, including 3D printers, are becoming progressively more common as a production method for components of, or entire packaging. ${ }^{19}$

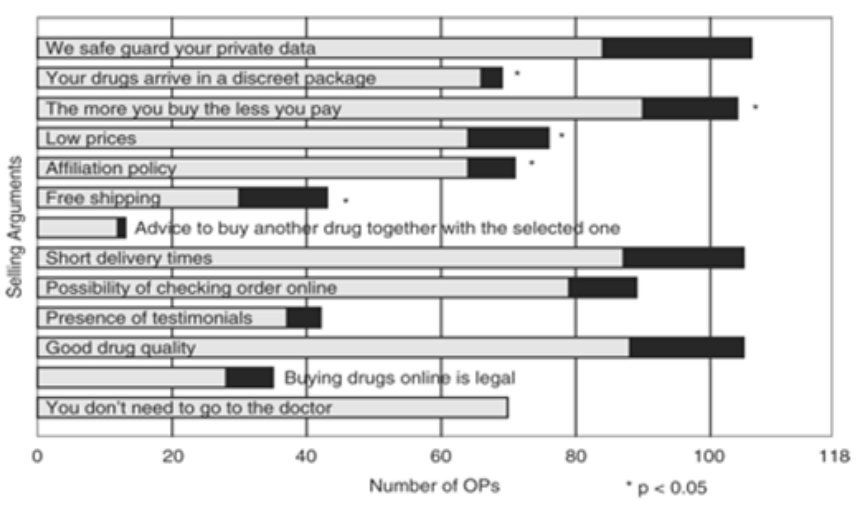

$\square$ No Prescription OPs

Figure 3 Common selling arguments used by OPs. ${ }^{46}$

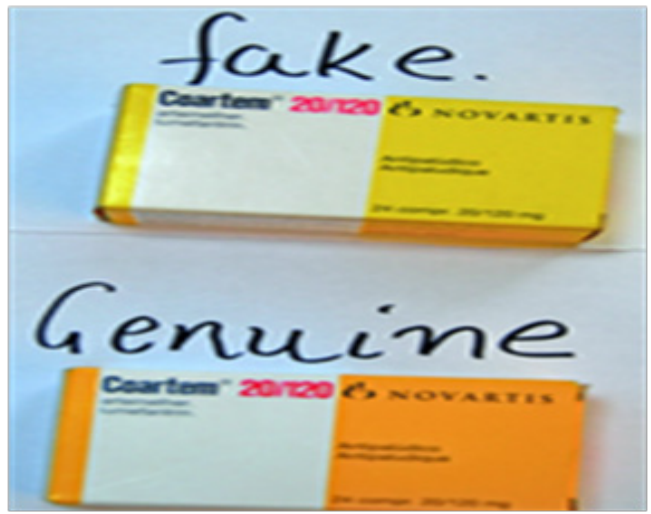

Figure 4 Counterfeit packaging recovered during Operation Zambezi in $2009 .{ }^{12}$

\section{Health information}

The disclosure of health information and side effects appears to remain highly varied across OPs with no consistency between those websites that require prescriptions and those that do not. Sildenafil, fluoxetine, tramadol and amitriptyline are widely available and popular drugs within the online market. When side effect disclosure was investigated for these drugs, a quarter of the 118 sample sites did not offer any form of statement. ${ }^{46}$ Of that sample, when compared against prescription OPs, non-prescription OPs showed a higher number of declarations for fluoxetine and amitriptyline, no significant difference for tramadol, but sildenafil was described as having far fewer risks. The same conclusion of results was found in another sample, this time of $161 \mathrm{OPs}$, where no declarations were found in a third of those investigated. Regarding the lifestyle drug, sildenafil, it was again found that a far lower proportion of non-prescription OPs declared side-effects compared to prescription OPs,${ }^{54}$ highlighting the idea that this is likely done intentionally due to the high profit capability of this drug. ${ }^{18}$

\section{Delivery into the UK}

Geographically diverse supply chains have resulted in counterfeit operations being possible at any step within the supply chain in whichever country that operation may be based. ${ }^{58}$ With the exception of small scale operations, illicit pharmaceuticals are not produced in the UK. They are more often imported through a range of trade routes; the widest known production countries are China and Russia, with India and Pakistan becoming increasingly common. ${ }^{27}$ It is recognised that a common technique used by criminals for the importation of counterfeit batches is to take advantage of supply routes that are already operational. Known as parallel trading, private traders within the European Union are able to legally purchase large quantities of pharmaceuticals in Member States at lower prices and then sell them in higher-priced Member States for a profit. ${ }^{27,59}$ The exportation countries experience shortages hence allowing falsified medications to be sold in order to fill the demand. Before re-sale, the licit pharmaceuticals are often re-packaged in order to help them sell in that particular country, but again this leaves them exposed to criminals who use this practice to disguise counterfeit batches and enter them into the legitimate supply chain. ${ }^{59}$ It is not unheard of though for OPs to operate out of normal suburban areas, an example of this was in 2008. A house in the East Midlands was under investigation by the MHRA and subsequently raided for being the physical location of an OP that was supposedly based in the USA. Prior to the raid, an intelligence officer on the case had successfully bought an Indian version of Viagra, which is illegal in the UK. ${ }^{30}$ Another instance that saw the UK being implicated in the trade was when the avian influenza (bird-flu) virus was at its peak. The MHRA detected multiple versions of the antiviral drug Tamiflu for sale from eighteen illegal OPs, three of which were based in the UK. ${ }^{60}$ The drug was found to contain no active ingredient with the bulk of the composition being made up of vitamin $\mathrm{C}$.

\section{What threats are posed?}

Ongoing development of internet pharmacies has seen doctorpatient relationships suffer and as "patient empowerment" grows, ${ }^{55}$ self-medication is becoming a serious risk to public safety. Even when a drug is legitimate, without regulation harmful side effects can occur. Serious cases have been reported whereby adverse effects caused by self-medication have resulted in consumers turning back to medical professionals. In the long term this will cause damaging effects to the healthcare system as it is likely that an increase amount of prescriptions will have to be handed out in comparison to what would have been initially required. Not only will the side effects require treatment but the original problem will still be present. This is particularly true with prescription drug addicts, who often abuse opiates intended for pain relief. Whereas they used to have to visit multiple doctors in order to receive valid prescriptions, they are now able to avoid this step and anonymously buy these controlled substances online. ${ }^{45}$ It is not uncommon for consumers to continue to take adulterated medication despite symptoms being evident. One example of this was in 2006 where a 58 -year-old Canadian woman died of metal toxicity after months of taking a sedative that she bought online, despite experiencing many side effects including hair loss and distorted vision. ${ }^{61}$ On examination by the FDA the likely cause of the metal contamination was due to the cutting agents used within the manufacturer of the pills. Not only are consumers putting their health at risk, they are vulnerable to becoming preyed on financially due to submitting their payment card information onto illegitimate sites. ${ }^{51}$ Many different forms on contraception are available online without the requirement of a prescription and the women who buy these products are putting themselves at serious risk..$^{62}$ Not only are counterfeits a danger but there are many known side effects that can vary significantly depending on the woman's health and should be carefully monitored by a physician. Without this professional guidance, not only is safety 
disregarded but a lack of education into the area persists, which is particularly concerning for younger generations. A study investigated the availability of these products to low and high risk individuals by purchasing through different aliases. ${ }^{47}$ It was found that regardless of individual, all medication could be obtained without the need of prescription, despite questionnaires being present that required the consumer to enter information including their blood pressure, age and weight.

\section{Action and the way forward}

\section{Organisations}

Strained resources and implications of ethics, including patient privacy, have limited the efforts to tackle this consistently growing and evolving issue. ${ }^{35}$ The International Criminal Police Organisation (INTERPOL) have undertaken multiple large scale operations in order to tackle pharmaceutical crime but have confirmed that there is a vital need for continued intervention. ${ }^{63}$ Operation Pangea, launched in 2008, was the first of its kind dealing with targeting internet pharmacies on an international scale. ${ }^{64}$ To date it has gained a significant following and is active in over 100 countries. ${ }^{58}$ Operation Mamba followed, with the goal being to intercept the trafficking activities of counterfeit medical products in Eastern Africa before they could reach developed countries whilst raising awareness. ${ }^{65}$ The MHRA launched a threepronged strategy in the same year, as summarised in Table 2, to tackle the problem. ${ }^{17}$ Success of this strategy was found to be problematic to quantify as the initial scale was unknown and hence the level of risk to consumers remains undetermined. To attempt to create solidarity worldwide, the WHO launched the Global Surveillance and Monitoring System for SSFFC medical products in 2013. To date 113 countries have joined forces with the combined aim to: ${ }^{1}$

Table 2 Summary of MHRA three-pronged strategy to combat counterfeiting ${ }^{17}$

\begin{tabular}{ll}
\hline Method & Key Aims \\
\hline \multirow{3}{*}{ Communication } & $\begin{array}{l}\text { To provide the public with enough accurate information } \\
\text { in a timely manner to provide reassurance and allow } \\
\text { them to make informed choices when obtaining } \\
\text { medication and medical products. }\end{array}$
\end{tabular}

To develop and maintain a working relationship with both industry and law enforcement to devise a list of medication and medical products that at a high risk of being counterfeited and targeted in the UK and focus resources on these throughout the supply chain.

Encourage reporting of all suspect medicine and medical products and refer to the MHRA for

Collaboration investigation.

Improve and expand the target market surveillance scheme.

Ensure the strategic threat assessment of the availability of counterfeit medicines and medical products in the UK is consistently updated and accurate.

Work alongside the WHO and other international organisations to combat the threat of counterfeit medicines and medical products.

Shift the counterfeit market so that there is an increased risk of prosecution in the UK.

Identify the key players within criminal gangs that Regulation operate the counterfeit market.

Bring about changes in both UK based and international legislation so there is an increased risk associated with counterfeiting and therefore a reduction in the market.
"Provide technical support in emergencies, link incidents between countries and regions, and issue WHO medical product alerts; and accumulate a validated body of evidence to more accurately demonstrate the scope, scale, harm caused by SSFFC medical products and identify the vulnerabilities, weaknesses and trends."

\section{Online}

The Partnership for Safe Medicines (PSM) has been working with online search engines to try to restrict advertising from unverified OPs. ${ }^{66}$ The organisation is attempting to create a uniform set of standards for paid advertising that will strive to ultimately eliminate unknowing customers purchasing products through illegitimate sites. The Royal Pharmaceutical Society of Great Britain (RPSGB) have implemented an internet pharmacy logo that aims to allow consumers to distinguish between genuine and counterfeit traders. ${ }^{7}$ Each logo has a unique number registered to a certain pharmacy (Figure 5); when clicked the RPSGB link you are directed to should match the number presented on the logo. From here, the consumer can check the records and authenticity of that provider. This, in theory, is a sensible safeguarding idea but the reality is that criminals will be able to recreate this logo and link to a standard that appears legitimate. The knowledge of this logo is also limited, with many consumers not understanding the significance.

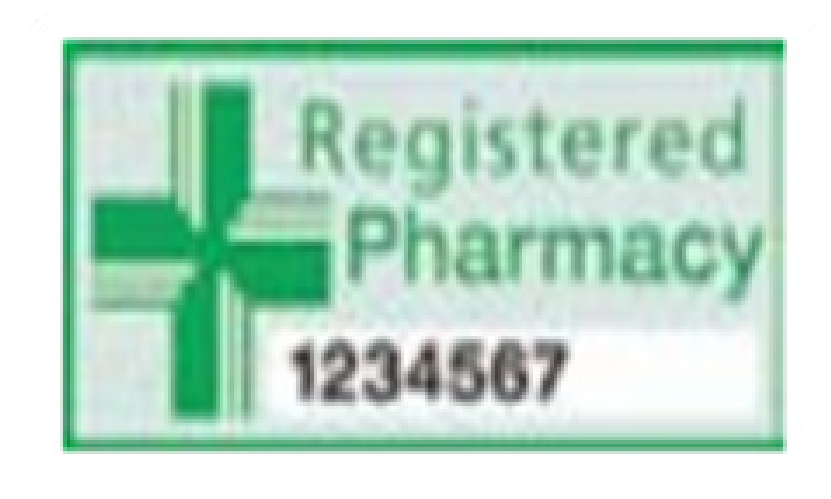

Figure 5 RSPGB logo given to genuine OPs, each having a unique number.?

\section{Chemical and visual}

Making dugs harder to duplicate has been a key focus of many pharmaceutical companies in recent years. Investigation into a covert or 'invisible' approach is underway whereby trace amounts of an inactive ingredient is added. This is known as a taggant and their aim is to allow for product authentication and easier detection of counterfeit products ${ }^{67}$ In addition to chemical tracing, implementations need to be in place for tracking licit batches so that it is easier to identify if an illicit batch has been introduced into the supply chain. Holograms and concealed codes on the tablets themselves have been suggested but it is radio frequency identification (for whole batches) and twodimensional bar codes (for individual packets) that show the most promise. ${ }^{35}$ The idea being that each manufacturer would have a unique identification code that remained the same between countries, that way unknown codes will highlight the presence of illicit batches. ${ }^{68-70}$

\section{Conclusion}

Dismantling the counterfeit market remains a challenge and despite more investigations and spot checks being undertaken, it is a complex market with grey areas that remain ambiguous to officials. ${ }^{22}$ Bryan Liang, the PSM Vice President and Executive Director of the Institute 
of Health Law Studies, recognised that the efforts to eliminate the counterfeit drug market are a long way from complete. In a 2010 statement he explained that "new legislation that prohibits financial transactions for drug sales of unlicensed pharmacies and creates criminal penalties for websites, search engines and individuals who participate in the sale of contraband or counterfeit drugs" needs to be implemented worldwide ${ }^{66}$ International collaboration is required with particular emphasis on the legal, forensic and scientific sectors. ${ }^{22}$ Whenever counterfeit products are seized they should be examined from a forensic intelligence perspective, with all data obtained being stored into a database which will help law enforcement tackle illicit manufacture and trafficking of these items. ${ }^{14}$ The chemical profile should be mapped along with a general physical examination of the medication and packaging. Batch numbers, best before dates and any other relevant information should be entered which, after time, will allow for quick searching of seized products against known counterfeit batches. This information could further be mapped to provide statistics on the production and distribution within the network and allow calculated attempts to dismantle the problem from the source to be made.

Although many international efforts are being made to reduce the trade, aggressive steps need to be taken to provide the public with a strong education campaign, as they are the final line of defence against these products. Consumers need to be aware of the frequency at which they circulate and if buying them willingly, they need to understand the severity of the possible health risks they are subjecting themselves and potentially their loved ones to. ${ }^{24}$ However, when involving the public, a balance needs to be found so as to not cause unnecessary panic surrounding this sensitive area. The information provided should be clear and insightful about the existence of counterfeit pharmaceuticals and what to do if they suspect they have been given one. It should also be made explicit that the individual risk is low and to not to lose faith in all local pharmacies. ${ }^{17}$ Pharmaceutical organisations should take a proactive approach by keeping in touch with their customers. The sale of all drugs manufactured should be tracked so that suspect counterfeit medication can be identified by unexplained drop of sales in a specific region or by an increase number of consumers complaining of an unexplained side effect. ${ }^{58}$ The sad truth is that counterfeit medications may always be a problem and multidimensional efforts are needed across a range of industry sectors. Batches of legitimate medication must be tracked from production; however it is not sufficient to limit this to the packaging, a method to track the products themselves must be produced..$^{33}$ The punishments received need to increase in severity but this will only help combat the issue when paired with robust enforcement, as an increase likelihood of being prosecuted and convicted needs to be present. ${ }^{29}$ Counterfeiters will always look for vulnerable targets to make quick profits from, but with increased global collaboration, new technologies and punishments that outweigh the perceived benefits, ${ }^{58}$ the level of the crime will decrease.

\section{Acknowledgements}

None.

\section{Conflict of interest}

Authors declare that there is no conflict of interest.

\section{References}

1. Substandard, spurious, falsely labelled, falsified and counterfeit (SSFFC) medical products. World Health Organisation. 2016.

2. Cockburn R, Newton PN, Agyarko EK, et al. The Global Threat of Counterfeit Drugs: Why Industry and Governments Must Communicate the Dangers. PLoS Medicine. 2005;2(4):e289.

3. Definitions of SSFFC Medical Products. World Health Organisation; 2016.

4. Cheng MM, Gedeon C. Counterfeit diabetes products and the ethical question of access. Future Medicine Ltd. 2015;5(5):341-347.

5. Land T. Combating Counterfeit Drugs. Nature. 1992;355(6357):192.

6. Gallagher J. Record 'fake drugs' haul worth $£ 16 \mathrm{~m}$ by UK agency. BBC news; 2015.

7. European Alliance for Access to Safe Medicines. The Counterfeiting Superhighway. 2008.

8. Gupta P, Singhal K, Pandey A. Counterfeit (Fake) Drugs \& New Technologies to Identify it in India. International Journal of Pharmaceutical Sciences and Research. 2012;3(11);4057-4064.

9. Coomber R, Pavlidis A, Santos GH, et al. The supply of steroids and other performance and image enhancing drugs (PIEDs) in one English city: Fakes, counterfeits, supplier trust, common beliefs and access. Performance Enhancement \& Health. 2014;3(3-4):135-144.

10. Newton PN, Green MD, Fernández FM, et al. Counterfeit anti-infective drugs. Lancet Infect Dis. 2006;6(9):602-613.

11. Rutter J, Bryce J. The Consumption of Counterfeit Goods. Sociology. 2008;42(6):1146-1164.

12. Growing threat from counterfeit medicines. World Health Organisation; 2010.

13. Liang BA. Over the virtual and geographic borders: understanding importation and counterfeit drugs. California Western International Law Journal. 2005;36(1):1-12.

14. Dégardin K, Roggo Y, Margot P. Forensic intelligence for medicine anticounterfeiting. Forensic Sci Int. 2015;248:15-32.

15. Rahman SZ, Gupta V, Sukhlecha A. Lifestyle Drugs: Concept and Impact on Society. Indian J Pharm Sci. 2010;72(4):409-413.

16. Jackson G, Patel S, Khan S. Assessing the problem of counterfeit medications in the United Kingdom. Int J Clin Pract. 2012;66(3): 241250 .

17. Chaplin S. The MHRA's three-pronged strategy to tackle counterfeits. Prescriber. 2008;19:51-53.

18. Orizio G, Merla A, Schulz PJ, et al. Quality of Online Pharmacies and Websites Selling Prescription Drugs: A Systematic Review. J Med Internet Res. 2011;13(3): 74 .

19. Wilson JM, Kinghorn R. The Global Risk of Product Counterfeiting: Facilitators of the Criminal Opportunity. Michigan State University Centre for Anti-Counterfeiting and Product Protection; 2015.

20. Reichel P, Albanese J. Handbook of Transnational Crime and Justice. United States of America: SAGE Publications; 2013.

21. Finlay B. D. Counterfeit drugs and national security. 2011.

22. Dégardin K, Roggo Y, Margot P. Understanding and fighting the medicine counterfeit market. J Pharm Biomed Anal. 2014;87:167-175. 
23. Harris J, Stevens P, Morris J. Keeping it Real: Combating the spread of fake drugs in poor countries. Health Issue. 2009.

24. Cheng MM. Is the Drugstore Safe? Counterfeit Diabetes Products on the Shelves. J Diabetes Sci Technol. 2009;3(6):1516-1520.

25. Van der Elst K, Davies N. Global Risks 2011. World Economic Forum; 2011. 1-60.

26. Clark F. Rise in online pharmacies sees counterfeit drugs go global Lancet. 2015;386(10001):1327-1328.

27. Antonopoulos GA, Hall A. Fake Meds Online. Palgrave Macmillan UK; 2016.

28. FDA Alerts U.S. Residents to Recall of Counterfeit "Lipitor" Sold in the United Kingdom. U.S. Food and Drug Administration. 2005.

29. Bate R. Making A Killing: The deadly implications of the counterfeit drug trade. $1^{\text {st }}$ edn. Washington D.C: American Enterprise Institute for Public Policy Research; 2008.

30. Clark E. Counterfeit medicines: the pills that kill. The Telegraph. 2008.

31. Counterfeit Medicines and Organised Crime. United Nations Interregional Crime and Justice Research Institute; 2012. 1-119.

32. Redpath $\mathrm{S}$. Trade in illegal medicine hits pharmaceutical sector. World Finance; 2012

33. Liang BA. Safety of drug supply: Tougher laws needed to stem counterfeit drug rings. 2006.

34. Manchikanti L. Prescription drug abuse: what is being done to address this new drug epidemic? Testimony before the Subcommittee on Criminal Justice, Drug Policy and Human Resources. Pain Physician. 2006;9(4):287-321.

35. Jack A. Bitter pills. The BMJ. 2007;335(7630):1120.

36. Newton PN, Green MD, Fernández FM. Impact of poor-quality medicines in the 'developing' world. Trends Pharmacol Sci. 2010;31(3):99-101.

37. Hanif M, Mobarak MR, Ronan A, et al. Fatal renal failure caused by diethylene glycol in paracetamol elixir: the Bangladesh epidemic. The BMJ. 1995;311(6997):88-91.

38. Misuse of Drugs Act 1971. 1971

39. Graham MR, Ryan P, Baker JS, et al. Counterfeiting in performance- and image-enhancing drugs. Drug Test Anal. 2009;1(3):135-142.

40. Chaudhry PE. The looming shadow of illicit trade on the internet. Business Horizons. 2017;60(1):77-89.

41. Mäkinen MM, Rautava PT, Forsström JJ. Do online pharmacies fit European internal markets? Health Policy. 2005;72(2):245-252.

42. Ostrom CM. Internet Medicine Opens 'Can Of Worms' -- Tremendous Potential For Good - And Harm. Seattle Times Company. 1999.

43. Martin J. Drugs on the Dark Net: How Cryptomarkets are Transforming the Global Trade in Illicit Drugs. UK: Palgrave Macmillan; 2014.

44. Fung $\mathrm{CH}$, Woo HE, Asch SM. Controversies and Legal Issues of Prescribing and Dispensing Medications Using the Internet. Mayo Clin Proc. 2004;79(2):188-194

45. Lineberry TW, Bostwick JM. Taking the Physician Out of "Physician Shopping": A Case Series of Clinical Problems Associated With Internet Purchases of Medication. Mayo Clin Proc. 2004;79(8):1031-1034.

46. Orizio G, Schulz P, Domenighini S, et al. Cyberdrugs: a cross-sectional study of online pharmacies characteristics. Eur $J$ Public Health. 2009;19(4):375-377.
47. Memmel LM, Miller L, Gardner J. Over-the-internet availability of hormonal contraceptives regardless of risk factors. Contraception. 2006;73(4):372-375.

48. Intellectual property crime and infringement. 2016.

49. Lay down the law on fakes. Nature Medicine. 2010;16(4):384.

50. Fake Medicine: Do you know what you're buying online? Medicines and Healthcare Products Regulatory Agency. 2009. 1-2.

51. Bostwick JM, Lineberry TW. Do cheap internet drugs threaten the safety of the doctor-patient relationship? Mayo Clinic Proceedings. 2007;6(1):9-13.

52. Orizio G, Schulz P, Domenighini S, et al. Online Consultations in Cyperpharmacies: Completeness and Patient Safety. Telemed J E Health. 2009;10(15):1022-1025.

53. Gurau C. Pharmaceutical marketing on the internet: marketing techniques and customer profile. The Journal of Consumer Marketing. 2005;22(7):421-428,438-439.

54. Orizio G, Rubinelli S, Schulz PJ, et al. Save 30\% if you buy today. Online pharmacies and the enhancement of peripheral thinking in consumers. Pharmacoepidemiology and Drug Safety. 2010;19(9):970-976.

55. Levaggi R, Orizio G, Domenighini S, et al. Marketing and pricing strategies of online pharmacies. Health Policy. 2009;92(2-3):187-196.

56. Armstrong K, Schwartz JS, Asch DA. Direct sale of sildenafil (Viagra) to consumers over the Internet. N Engl J Med. 1999;341(18):1389-1392.

57. Shanley A. Chasing a Moving Target for Counterfeiting and Illegal Diversion. Pharmaceutical Technology. 2016;40(10):52-57.

58. Campbell D. Fake Medications, Real Solutions. Pharmaceutical Executive. 2015;35(5):42-43.

59. Differences in costs of and access to pharmaceutical products in the EU. European Parliament; 2011. 1-92.

60. Harris Cheng M. Fake "Tamiflu" available on the internet. The Lancet Infectious Diseases. 2006;6(2):79.

61. Ligaya A. Counterfeit drugs caused woman's death, coroner concludes. The Globe and Mail. 2007.

62. Liang BA, Mackey TK, Lovett KM. Suspect online sellers and contraceptive access. Contraception. 2012;86(5):551-556.

63. Pharmaceutical Crime: Operations. INTERPOL. 2016.

64. Illegal online medicine suppliers targeted in first international Internet day of action. INTERPOL. 2008.

65. East Africa's Zanzibar Declaration to boost fight against counterfeit medical products and pharmaceutical crimes. INTERPOL. 2010.

66. Partnership for Safe Medicines applauds Googles updated U.S pharmaceutical advertising policy. Partnership for Safe Medicines. 2010.

67. Guidance for Industry: Incorporating Physical and Chemical Identifiers in Solid Oral Dosage Form Drug Products for Anticounterfeiting. U.S. Department of Health and Human Services Food and Drug Administration. 2011. 1-10.

68. Antonopoulos GA. Hall A. Fake Meds Online. Palgrave Macmillan. UK; 2016.

69. Adams JU. An Op-Ed concerning steroids and the law: How the Internet has changed illegal drug trade and its prosecution. Physiol Behav. 2010;100(3):205-207.

70. FAKE DRUGS ON THE WEB. International institute of research against counterfeit medicines. 2013. 